\title{
Non-surgical Management Should be First-line Therapy for Breast Abscess: Reply
}

\author{
Julie A. Margenthaler
}

Published online: 9 April 2010

(c) Société Internationale de Chirurgie 2010

We appreciate the experience of Elder and Brennan [1], who report that the majority of patients with breast abscesses who are treated at their institution are successfully treated with serial percutaneous aspiration under ultrasound guidance, in combination with appropriate antibiotic therapy. We recognize that a major limitation of our recent article [2] is the inability to account for patients who may be undergoing nonoperative treatment for their breast abscesses. Percutaneous aspiration has become more common at our institution as well, but we do not currently record percutaneous procedures in our surgical database and cannot comment on the effectiveness in comparison to open drainage.

We also acknowledge that there are multiple reports regarding the potential effectiveness of this non-surgical method [3-8]. However, there are many limitations to those studies as well. They include small numbers of patients who underwent a variety of techniques with varying degrees of success. For instance, Hook et al. [6] reported their experience with 13 patients. Percutaneous drainage was successful in 7 patients who had small abscesses $(<2.4 \mathrm{~cm})$, but 5 of 6 patients with abscesses $>2.4 \mathrm{~cm}$ required surgical therapy when percutaneous methods failed. Berna-Serna et al. [7] also reported poor success with percutaneous drainage when the abscesses were $>3 \mathrm{~cm}$. As a result, they employed catheter tube placement in abscesses $>3 \mathrm{~cm}$. While percutaneous techniques may prove to be appropriate for a large number of patients, anecdotal experience and the data provided in these small published series are insufficient evidence that

J. A. Margenthaler $(\square)$

Department of Surgery, Washington University School

of Medicine, 660 S. Euclid Ave., Campus Box 8109, St Louis, MI 63110, USA

e-mail: margenthalerj@wudosis.wustl.edu percutaneous methods are as effective as surgical incision and drainage.

To answer this question, a prospective trial, powered with adequate patient numbers, would be necessary. This would allow us to determine the abscess characteristics (size, loculation, location in breast) that may portend a better or worse outcome following percutaneous techniques. Such a trial would also allow the development of guidelines and standardization of techniques to be employed based on the specific patient and abscess characteristics. However, until such data are available, it is unclear whether percutaneous methods of abscess management are as effective as the gold standard of definitive surgical treatment.

\section{References}

1. Elder EE, Brennan M (2010) Non-surgical management should be first-line therapy for breast abscess. World J Surg. doi:10.1007/ s00268-010-509-1

2. Bharat A, Gao F, Aft RL et al (2009) Predictors of primary breast abscesses and recurrence. World J Surg 33:2582-2586

3. Berna JD, Garcia-Medina V, Madrigal M et al (1996) Percutaneous catheter drainage of breast abscesses. Eur J Radiol 21:217-219

4. Tan SM, Low SC (1998) Non-operative treatment of breast abscesses. Aust N Z J Surg 68:423-424

5. Dixon JM (1994) ABC of breast diseases: breast infection. BMJ 309:946-949

6. Hook GW, Ikeda DM (1999) Treatment of breast abscesses with US-guided percutaneous needle drainage without indwelling catheter placement. Radiology 213:579-582

7. Berna-Serna JD, Madrigal M (2004) Percutaneous management of breast abscesses: an experience of 39 cases. Ultrasound Med Biol $30: 1-6$

8. Christensen AF, Al-Suliman N, Nielsen KR et al (2005) Ultrasound-guided drainage of breast abscesses: results in 151 patients. Br J Radiol 78:186-188 